\title{
Bagana de carnaúba como substrato na produção de mudas de açaí cultivar BRS-Pará
}

O açaizeiro é uma palmeira com elevado potencial comercial e que apresenta propriedades químicas benéficas à saúde humana. Neste trabalho objetivou-se avaliar a produção de mudas de açaí cultivar BRS-Pará produzidas em substratos à base de bagana de carnaúba em diferentes proporções. 0 experimento fo realizado em casa de vegetação, adotou-se o delineamento inteiramente casualizado, com 6 tratamentos, 4 repetições. As formulações de substratos foram $0 \%$, $20 \%, 40 \%, 60 \%, 80 \%$ e $100 \%$ de bagana de carnaúba acrescidos de solo. Avaliou-se: índice de velocidade de emergência, percentual de germinação (\%), área folia $(\mathrm{cm} 2)$; altura da planta $(\mathrm{cm})$; diâmetro do caule $(\mathrm{mm})$; comprimento radicular $(\mathrm{cm})$; volume radicular $(\mathrm{cm} 3)$, massa seca da raiz e da parte aérea $(\mathrm{g})$. Ao término constatou-se que a utilização de diferentes proporções de bagana de carnaúba afetou na produção de mudas de açaí 'BRS-Pará'. Não apresentaram efeito significativo $(p>0,05)$ para o índice de velocidade de emergência (IVE) e germinação (G\%). Entretanto, houve efeitos sobre o enraizamento principalmente no comprimento radicular e seu volume. Através das análises observou-se efeito significativo $(p<0,01)$ pelo teste $F$, para área foliar, altura da planta, diâmetro do caule, comprimento radicular, volume radicular, massa seca da parte aérea, massa seca sistema radicular e índice de qualidade de Dickson. A bagana de carnaúba pode ser utilizada como substrato para produção de mudas de açaí 'BRS-Pará' nas proporções de $40 \%, 60 \%$ e $80 \%$. Entretanto, recomenda-se o uso de substrato de BC na proporção de $40 \%$ acrescido de solo, por apresentar uma menor quantidade do substrato.

Palavras-chave: Copernicia prunifera Mill; Euterpe oleracea Mart.; Muda de qualidade; Composto orgânico.

\section{Carnaúba bagana as a substrate in the production of açaí cultivar BRS-Pará}

\begin{abstract}
The açaí tree is a palm tree with high commercial potential and has chemical properties beneficial to human health. This work aimed to evaluate the production of açaí seedlings cultivar BRS-Pará produced in substrates based on carnauba bagana in different proportions. The experiment was carried out in a greenhouse, a completely randomized design was adopted, with 6 treatments, 4 repetitions. The substrate formulations were $0 \%, 20 \%, 40 \%, 60 \%, 80 \%$ and $100 \%$ carnauba bagana plus soil. It was evaluated: emergence speed index, germination percentage (\%), leaf area (cm2); plant height $(\mathrm{cm}) ;$ stem diameter $(\mathrm{mm}) ;$ root length $(\mathrm{cm}) ;$ root volume $(\mathrm{cm} 3)$, root and shoot dry mass $(\mathrm{g})$. At the end, it was found that the use of different proportions of carnauba bagana affected the production of aça seedlings 'BRS-Pará'. There was no significant effect $(p>0.05)$ for the emergence speed index (IVE) and germination (G\%). However, there were effects on rooting mainly on root length and volume. Through the analyzes, a significant effect $(p<0.01)$ was observed by the $F$ test, for leaf area, plant height, stem diameter, root length, root volume, dry mass of the aerial part, dry mass of the root system and index of Dickson quality. The carnauba bagana can be used as a substrate for the production of açaí seedlings 'BRS-Pará' in the proportions of $40 \%, 60 \%$ and $80 \%$. However, it is recommended to use BC substrate in the proportion of $40 \%$ plus soil, as it has a smaller amount of the substrate.
\end{abstract}

Keywords: Copernicia prunifera Mill; Euterpe oleracea Mart.; Changes in quality; Organic compound.

Topic: Agroecologia

Reviewed anonymously in the process of blind peer
Received: 02/08/2020

Approved: 19/09/2020
Marcos de Oliveira Sousa (DD)

Universidade Federal do Maranhão, Brasil http://lattes.cnpq.br/6537426013761119 http://orcid.org/0000-0002-8331-4325 markos-1520101@hotmail.com

Raissa Rachel Salustriano da Silva Matos (iD Universidade Federal do Maranhão, Brasil $\frac{\text { http://lattes.cnpq.br/0720581765268326 }}{\text { http://orcid.org/0000-0002-8908-2297 }}$ raissasalustriano@yahoo.com.br

João Pedro Santos Cardoso (iD Universidade Federal do Maranhão, Brasi http://lattes.cnpq.br/1057085207810749 http://orcid.org/0000-0003-4465-8712 joaopedrocardos020@hotmail.com
Kleber Veras Cordeiro

Universidade Federal do Maranhão, Brasil http://lattes.cnpq.br/7585883012639032 http://orcid.org/0000-0003-0149-8819 kleberverascordeiro@hotmail.com

Larissa Macelle de Paulo Barbosa Universidade Federal do Maranhão, Brasil http://lattes.cnpq.br/1324276797717597 http://orcid.org/0000-0002-2568-2373 larissamacelle@hotmail.com

Janaiane Ferreira dos Santos (iD)

Universidade Federal do Maranhão, Brasi http://lattes.cnpq.br/9678500549107690 http://orcid.org/0000-0003-0152-5725 janaianeferreira@gmail.com

\section{Analya Roberta Fernandes Oliveira (iD Universidade Federal do Ceará, Brasil http://lattes.cnpq.br/9601701413016553 ttp://orcid.org/0000-0002-6360-5707 analyaroberta_fernandes@hotmail.com \\ Francisca Gislene Albano Machado Universidade Federal do Ceará, Brasil http://lattes.cnpq.br/3728012118132276 http://orcid.org/0000-0003-3614-7488 gislene.fga@gmail.com \\ Nayron Alves Costa \\ Universidade Federal do Maranhão, Brasi http://lattes.cnpq.br/1875704699671024 http://orcid.org/0000-0003-4921-9428} nayron@gmail.com
Milena Maria Tomaz de Oliveira (1D) Ben-Gurion University of the Negev, Israe http://lattes.cnpq.br/3709791112709404 http://orcid.org/0000-0001-7345-1003 phdmilenaoliveira@gmail.com

DOI: 10.6008/CBPC2179-6858.2020.005.0012

\section{Referencing this:}

SOUSA, M. O.; MATOS, R. R. S. S.; CARDOSO, J. P. S.; CORDEIRO, K. V.; BARBOSA, L. M. P.; SANTOS, J. F.; OLIVEIRA, A. R. A.; MACHADO, F. G. A.; COSTA, N. A.; OLIVEIRA, M. M. T.. Bagana de carnaúba como substrato na produção de mudas de açaí cultivar BRS-Pará. Revista Ibero Americana de Ciências Ambientais, v.11, n.5, p.113-122, 2020 DOI: http://doi.org/10.6008/CBPC2179-6858.2020.005.0012 


\section{INTRODUÇÃO}

Na floresta Amazônica o açaizeiro (Euterpe oleracea Mart.) destaca-se por ser uma palmeira altamente produtiva, tanto em frutos como em gêneros derivados da planta (NEVES et al., 2015). O fruto, matéria-prima para a obtenção do suco de açaí, bebida-símbolo do Estado do Pará, é o principal produto oriundo da palmeira (SILVESTRE et al., 2016). O extrativismo do açaí é uma atividade típica da agricultura familiar. Cerca de $80 \%$ do açaí é obtido de extrativismo, enquanto apenas $20 \%$ provêm de açaizais manejados e cultivados (NOGUEIRA et al., 2005).

O Brasil é o maior produtor, consumidor e exportador do fruto do açaí (PORTINHO et al., 2012). O açaizeiro vem conquistando o mercado nacional mediante comercialização da bebida in natura (suco), bem como da congelada. Essa bebida é obtida pelo processamento da parte comestível dos seus frutos, que são denominados açaí.

O substrato para a produção de mudas tem finalidade de garantir o desenvolvimento de uma planta com qualidade, em curto período de tempo, e baixo custo, reunindo características físicas (retenção de umidade) e químicas (disponibilidade de nutrientes), de modo que proporcionem o desenvolvimento adequado das mudas, permitindo boa formação do sistema radicular e da parte aérea (CUNHA et al., 2006).

Tendo em vista essas características, uma alternativa para a produção de mudas no maranhão é a utilização de substratos regionais, a exemplo da bagana de carnaúba, sendo um material leve, que acrescenta porosidade ao substrato (GUERRINI et al., 2004). A bagana de carnaúba apresenta pH na faixa de 5,8 e elevados teores de macronutrientes (SILVA JÚNIOR et al., 2014) que somados com a sua porosidade, tornarse um excelente substrato. A bagana de carnaúba (Copernicia prunifera Mill.) possui potencial para uso como componente de substrato, com resultados promissores para algumas culturas como berinjeleira (BEZERRA et al., 2009), noni (SOUSA et al., 2013), helicônias (BECKMANN-CAVALCANTE et al., 2011) e tomateiro (SILVA JÚNIOR et al., 2014).

Uma das alternativas propostas para reduzir o custo de produção de mudas é o uso de substratos alternativos advindos de componentes orgânicos, a bagana de carnaúba traz como vantagem a melhoria das características físicas, químicas e biológicas do solo. A bagana vem sendo muito utilizada para produção de mudas na região nordestina pois o mesmo apresenta ótimos resultados na produção de mudas de variadas frutíferas. Com o presente trabalho teve-se o objetivo de avaliar o percentual germinativo, produção, crescimento, e desenvolvimento das mudas de açaí (Euterpe oleracea Mart.) cultivar BRS-Pará em diferentes proporções de substratos a base de bagana de carnaúba (Copernicia prunifera Mill.).

\section{MATERIAIS E MÉTODOS}

O experimento foi desenvolvido de setembro a dezembro de 2018 , em estufa $(70 \%$ de sombreamento) Centro de Ciências Agrárias e Ambientais, da Universidade Federal do Maranhão, situado no município de Chapadinha/MA, cujas coordenadas 0344'30" S e 4321'37" O, 105 m de altitude em relação ao nível do mar, o município de Chapadinha possui uma área de $3247 \mathrm{~km}^{2}$, uma população de 
aproximadamente 77684 habitantes e uma densidade demográfica de 22,56 habitantes $\mathrm{km}^{2}$ (IBGE, 2015). 0 clima, segundo a classificação de Köppen, é do tipo tropical quente e úmido (Aw), com temperatura média anual superior a $27^{\circ} \mathrm{C}$ e precipitação pluvial média anual de $1835 \mathrm{~mm}$ (PASSOS et al., 2016).

Para a produção das mudas de açaí, foi adotado o delineamento inteiramente casualizado, com 6 tratamentos, 4 repetições e 4 mudas por repetição totalizando assim 96 mudas. Os tratamentos consistiram em diferentes formulações de substrato com $0 \%, 20 \%, 40 \%$ 60\%, $80 \%$ e $100 \%$ de bagana de carnaúba, acrescidos de solo.

A bagana obtida da agroindústria da carnaubeira, proveniente do município de Vargem Grande, MA, foi triturada mecanicamente em picador de forragem (TRF-50, TRAPP), e posteriormente peneirada com auxílio de peneira de $5 \mathrm{~mm}$, para fácil homogeneização na formulação do substrato. Os sacos de polietileno na dimensão de $12 \times 20 \mathrm{~cm}$ foram preenchidos com os substratos correspondentes aos tratamentos, sendo semeadas apenas uma semente de açaí cultivar 'BRS Pará' a $1 \mathrm{~cm}$ de profundidade por recipiente. A irrigação foi realizada duas vezes ao dia, por meio de regador manual com capacidade de $5 \mathrm{~L}$, e aos 105 dias após o plantio foram feitas as análises em laboratório das mudas.

No solo utilizado foi realizada análise granulométrica que compõem: $384 \mathrm{~g}$ areia grossa $\mathrm{kg}^{-1} ; 336 \mathrm{~g}$

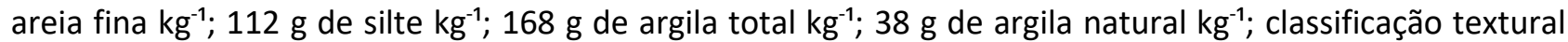

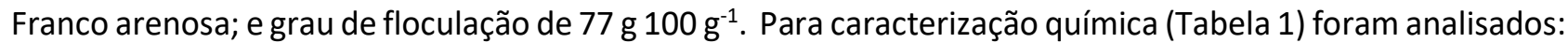
pH, matéria orgânica (M.O.) e teores totais de macronutrientes: nitrogênio (N), fósforo (P), potássio (K), cálcio (Ca), magnésio (Mg) e enxofre (S) de acordo com (MAPA, 2007).

Tabela 1: Valores de $\mathrm{pH}$, matéria orgânica (M.O.) e teores totais de nitrogênio $(\mathrm{N})$, fosforo (P), potássio (K), cálcio (Ca), magnésio $(\mathrm{Mg})$ e enxofre $(\mathrm{S})$ dos substratos à base de bagana de carnaúba $(\mathrm{BC})$, acrescido de solo.

\begin{tabular}{|c|c|c|c|c|c|c|c|c|}
\hline Substrato & $\mathrm{pH}$ & $\begin{array}{l}\text { M.O. } \\
\text { g kg-1 }^{-1}\end{array}$ & $\begin{array}{l}\mathrm{N} \\
\mathrm{g} \mathrm{kg}^{-1}\end{array}$ & $\begin{array}{l}\mathrm{P} \\
\mathrm{mg} \mathrm{kg}^{-1}\end{array}$ & $\mathrm{~K}$ & $\begin{array}{l}\mathrm{Ca} \\
\mathrm{kg}^{-1}-\end{array}$ & $\mathrm{Mg}$ & $S$ \\
\hline $0 \% \mathrm{BC}$ & 4,0 & 0,61 & 1,23 & 14 & 0,67 & 1,60 & 1,00 & 3,8 \\
\hline $20 \%$ BC & 5,1 & 60,67 & 3,92 & 6 & 0,63 & 2,90 & 0,50 & 4,3 \\
\hline $40 \% \mathrm{BC}$ & 4,9 & 73,82 & 5,36 & 12 & 0,72 & 4,50 & 1,30 & 6,8 \\
\hline $60 \% \mathrm{BC}$ & 5,0 & 95,22 & 6,89 & 23 & 1,28 & 5,90 & 1,40 & 8,9 \\
\hline $80 \%$ BC & 5,1 & 114,26 & 9,28 & 42 & 2,21 & 7,00 & 3,10 & 12,7 \\
\hline $100 \% \mathrm{BC}$ & 5,3 & 598,86 & 4,02 & 89,0 & 3,88 & 19,80 & 10,40 & 34,60 \\
\hline
\end{tabular}

Para caracterização física (Tabela 2), foram realizadas analise de densidade global, densidade de partícula e porosidade, determinados conforme procedimentos descritos por (SCHMITZ et al., 2002).

Tabela 2: Densidade global (DG), densidade de partícula (DP) e porosidade (P), dos substratos à base de bagana de carnaúba (BC), acrescido de solo.

\begin{tabular}{llll}
\hline Substratos & Densidade $\left(\mathrm{g} / \mathrm{cm}^{3}\right)$ & Porosidade $(\%)$ \\
& DG & DP & \\
\hline $0 \%$ BC & 1,28 & 2,64 & 51,53 \\
$20 \%$ BC & 1,17 & 2,61 & 55,33 \\
$40 \%$ BC & 0,99 & 2,42 & 59,26 \\
$60 \%$ BC & 0,78 & 1,98 & 60,78 \\
$80 \%$ BC & 0,56 & 1,77 & 68,53 \\
$100 \%$ BC & 0,29 & 0,90 & 70,20 \\
\hline
\end{tabular}

Para determinação dos efeitos dos respectivos tratamentos na formação de mudas de açaí, avaliouse aos 105 dias após a semeadura: emergência de plântulas (\%): contagem do número de plântulas emergidas 
a cada dois dias, a partir do início da emergência até a estabilização; índice de velocidade de emergência: calculado de acordo com Maguire (1962) após a estabilização da emergência de plântulas.

Ao término do experimento, foram avaliadas ainda: altura de planta $(\mathrm{cm})$ : determinada do nível do solo ao ápice da planta com o auxílio de uma régua milimetrada; diâmetro do caule $(\mathrm{mm})$ : obtido com paquímetro digital $\left(0,01-300 \mathrm{~mm}\right.$, Digimess $\left.{ }^{\circ}\right)$ à $5 \mathrm{~cm}$ da superfície do substrato. No laboratório foram quantificadas as seguintes variáveis: comprimento radicular $(\mathrm{cm})$ : medido com auxílio de uma régua graduada em milímetros; volume radicular $\left(\mathrm{cm}^{3}\right)$ : realizado por meio de medição do deslocamento da coluna de água em proveta graduada; área foliar $\left(\mathrm{cm}^{2}\right)$ : determinada por intermédio do programa computacional Image $J^{\circ}$; massa seca da parte aérea $(\mathrm{g})$; massa seca do sistema radicular (g): sendo o material vegetal conduzido à estufa com circulação forçada de ar à temperatura de 65 @C até atingir massa constante e pesada em balança com precisão de $0,01 \mathrm{~g}$.

Determinou-se ainda o índice de qualidade de Dickson (IQD), por meio da fórmula descrita por Dickson et al. (1960), como demonstra a Equação 1:

$$
\mathrm{IQD}=\frac{\mathrm{MST}(\mathrm{g})}{\mathrm{AP}(\mathrm{cm}) / \mathrm{DC}(\mathrm{mm})+\mathrm{MSPA}(\mathrm{g}) / \mathrm{MSR}(\mathrm{g})}
$$

Os dados foram submetidos à análise de variância pelo teste ' $F$ ', para diagnóstico de efeito significativo, e os tratamentos comparados entre si pelo teste de Tukey, ao nível de $5 \%$ de probabilidade para avaliação de diferença significativa através do programa computacional Assistat ${ }^{\circ} 7.7$ (SILVA et al., 2016).

\section{RESULTADOS E DISCUSSÃO}

Através das análises estudadas (Tabela 3), a utilização de diferentes proporções do substrato de bagana de carnaúba (BC) na produção de mudas de açaí da cultivar BRS-Pará, não apresentaram efeito significativo $(p>0,05)$ para a germinação (G\%) e o índice de velocidade de emergência (IVE).

Tabela 3: Valor de F e significância dos fatores para variáveis germinação (G\%), índice de velocidade de emergência (IVE), área foliar (AF), altura da planta (AP), diâmetro do caule (DC), comprimento radicular (CR), volume radicular (VR), massa seca da parte aérea (MSPA), massa seca do sistema radicular (MSSR) e índice de qualidade de Dickson (IQD) de mudas de açaizeiro.

\begin{tabular}{|c|c|c|c|c|c|c|c|c|}
\hline \multirow{2}{*}{ FV } & \multirow{2}{*}{$\mathrm{GL}$} & \multicolumn{7}{|l|}{ FCAL } \\
\hline & & G\% & IVE & $\mathrm{AF}$ & AP & DC & $\mathrm{CR}$ & F.TAB \\
\hline Substrato & 5 & 0,84 & 1,55 & 6,38 & 4,21 & 10,23 & 3,97 & 2,57 \\
\hline Resíduo & 18 & - & - & - & - & - & - & - \\
\hline CV\% & & 11,77 & 21,81 & 18,96 & 9,32 & 5,34 & 12,49 & - \\
\hline SIG & $* *$ & ns & ns & $* *$ & $* *$ & $* *$ & $* *$ & - \\
\hline \multirow{2}{*}{ FV } & \multirow{2}{*}{$\mathrm{GL}$} & \multicolumn{7}{|l|}{ FCAL } \\
\hline & & VR & MSPA & MSSR & IQD & F.TAB & & \\
\hline Substrato & 5 & 7,43 & 8,98 & 11,76 & 5,50 & 2,57 & & \\
\hline Resíduo & 18 & - & - & - & - & - & & \\
\hline CV\% & & 16,22 & 11,58 & 10,90 & 11,68 & - & & \\
\hline SIG & & $* *$ & $* *$ & $* *$ & $* *$ & - & & \\
\hline
\end{tabular}

$\overline{F V}=$ fonte de variação; $\mathrm{GL}=$ grau de liberdade; $\mathrm{CV}=$ coeficiente de variação; $F C A L=F$ calculado; $F T A B=F$ tabelado; $S I G=$ 
significância; ${ }^{* *}=$ significativo ao nível de $1 \%$ de probabilidade $(p<0,01)$; ns=não significativo $(p>=0,05)$.

Entretanto, houve efeito significativo $(p<0,01)$ para área foliar $(A F)$, altura da planta $(A P)$, diâmetro do caule (DC), comprimento radicular (CR), volume radicular (VR), massa seca da parte aérea (MSPA), massa seca sistema radicular (MSSR) e para o índice de qualidade de Dickson (IQD).

Na \%G (Figura 1A) e IVE (Figura 1B) não foram observados nenhum efeito significativo entre os tratamentos. Estes resultados demonstram que o substrato orgânico estudado (bagana de carnaúba), possui características que favorecem o processo de germinação, que para Farias et al. (2012) são principalmente, suprimento de água e fornecimento de oxigênio. Segundo Carvalho et al. (2000), uma boa capacidade de retenção de água do substrato mantém a água nas proximidades das sementes, o que é desejável para obtenção da uniformidade de emergência e um bom estande.
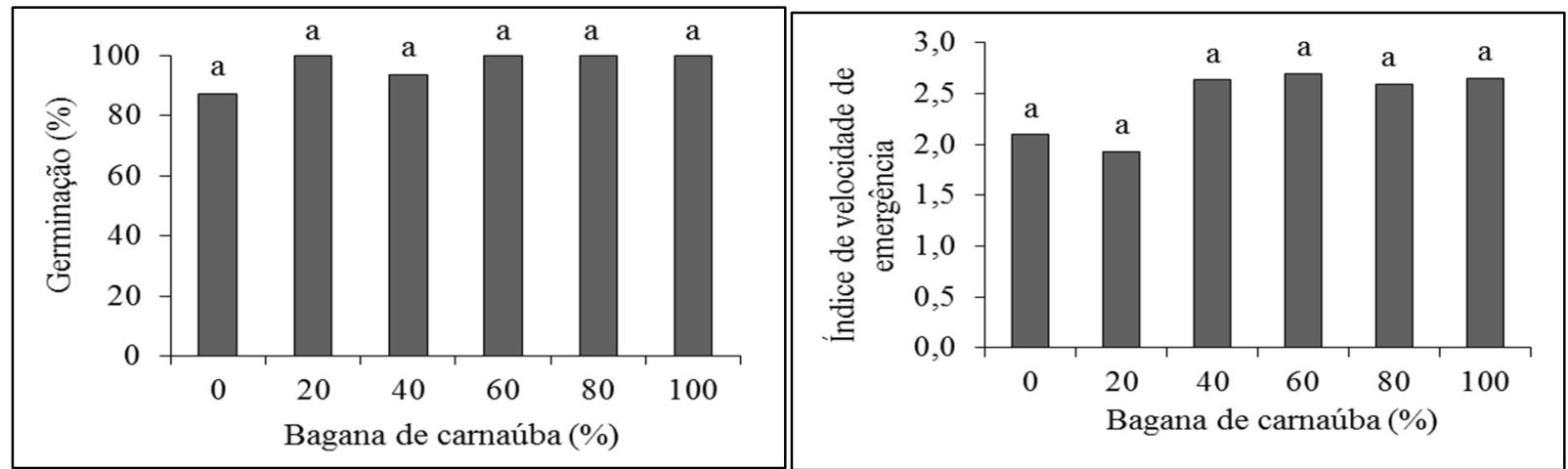

Figura 1: Porcentagem de germinação (A) e índice de velocidade de emergência (B) de mudas de açaí cultivar BRSPará, em função de substratos com proporções de bagana de carnaúba acrescidos de solo.

De acordo com Bezerra et al. (2009) avaliando substratos à base de compostos orgânicos em mistura com diferentes resíduos (incluindo bagana de carnaúba e casca de arroz carbonizada) para produção de mudas de berinjela também não encontraram diferenças na \%G entre os substratos alternativos avaliados e o substrato comercial "Hortimix solanáceas".

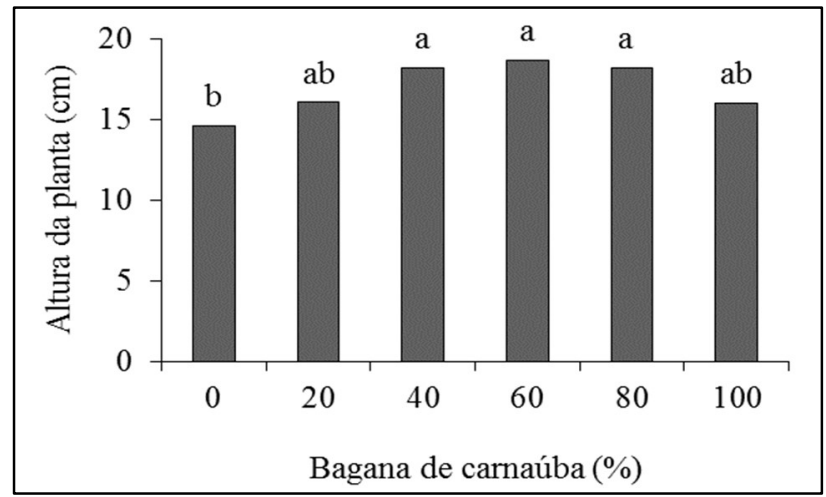

Figura 2: Altura da planta de mudas de açaí cultivar BRS-Pará, em função das diferentes proporções de bagana de carnaúba.

Os tratamentos intermediários, como mostra na (Figura 2), destacaram-se em relação a variável AP, estatisticamente elas foram iguais, o alto teor de fósforo presente na BC se comparando com aquele presente no solo influencia no crescimento da planta nesses respectivos tratamentos. Maiores doses de fosforo 
proporcionam maiores valores de AP (SARAIVA et al., 2011). No estudo feito por Welter et al. (2014) encontrou-se altura de mudas de Euterpe oleracea de $21,26 \mathrm{~cm}$, resultado superior ao utilizar doses de pó de rocha (basalto), variando o tamanho da partícula, isso aos 180 dias após a repicagem da muda de açaí.

Corroborando com estes resultados, Silva Júnior et al. (2014) estudando o aproveitamento de materiais alternativos na produção de mudas de tomateiro, verificaram que resíduo de carnaúba com adição casca de arroz e resíduo de carnaúba semidecomposto resultaram em maiores alturas de plantas quando comparado aos demais materiais utilizados.

Substratos de fontes orgânicas decompostas possibilitam maior retenção de umidade nos recipientes e maior fornecimento de nutrientes essenciais (PAIVA et al., 2011), favorecendo assim maior crescimento das mudas. $\mathrm{O}$ tratamento com $0 \%$ de $\mathrm{BC}$ acrescido de solo obteve o menor resultado com apenas $14 \mathrm{~cm}$ de altura, isso provavelmente se deu por conta do baixo teor de nutrientes presente no solo inclusive o fósforo.

Para o CR, o tratamento contendo $80 \%$ de BC acrescido de solo, foi o que apresentou mudas com o sistema radicular mais desenvolvido, com uma média de $26,38 \mathrm{~cm}$ como pode ser observado na (Figura 3A). O resultado obtido pelo substrato pode estar associado as condições físicas (Tabela 2), sendo que o aumento da concentração da bagana de carnaúba na composição do substrato estudado propiciou uma maior porosidade e consequentemente, uma maior aeração, segundo Lima et al. (2006), que observaram que a aeração do substrato é um dos mais importantes fatores envolvidos no sistema radicular.
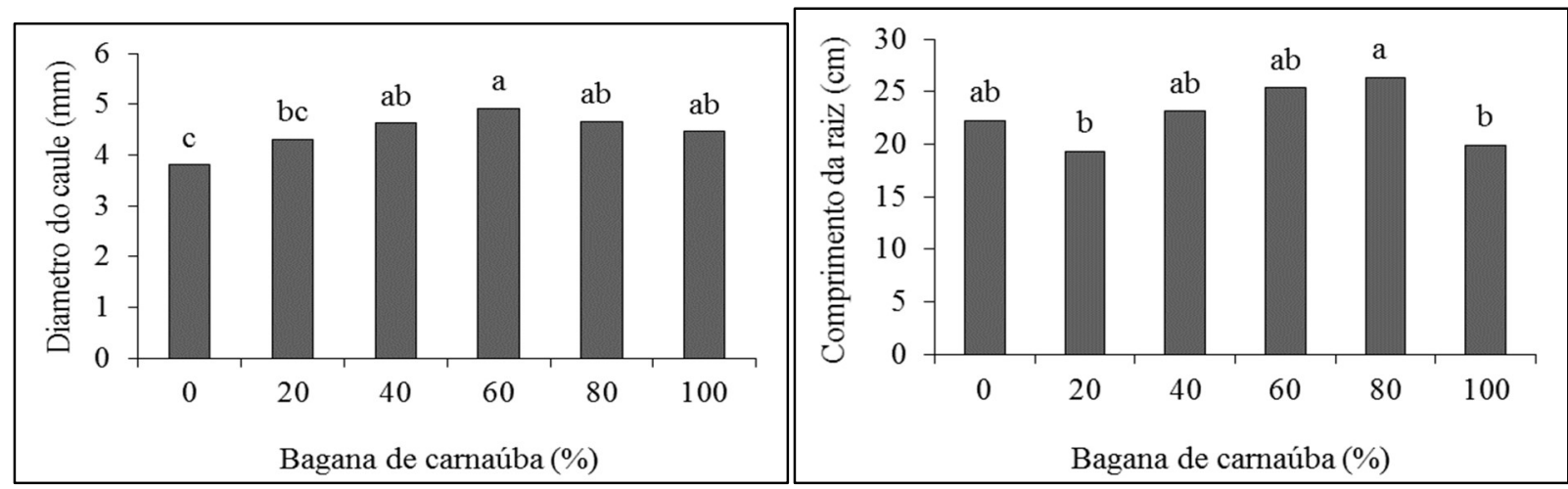

Figura 3: Comprimento da raiz (A) e diâmetro do caule (B) de mudas de açaí cultivar BRS-Pará, em função de substratos com proporções de bagana de carnaúba acrescidos de solo.

Quanto ao DC (Figura 4B) o tratamento que proporcionou um melhor resultado foi o substrato contendo $60 \%$ de $B C$ acrescido de solo, com 4,92 $\mathrm{mm}$. Os resultados obtidos neste trabalho são positivos se comparando com o de Oliveira et al. (2011), no estado da Paraíba, estudando diferentes doses de nitrogênio e potássio, encontraram um valor médio máximo de 3,2 mm de diâmetro em um período de 120 dias.

Gonzaga et al. (2016) estudando recipientes e substratos para produção de mudas de Hymenaea courbaril L. observaram que os substratos contendo areia e solo proporcionaram as menores médias de desenvolvimento de diâmetro do colo, concordando com os resultados encontrados na execução deste experimento. Segundo Silva (2015), substratos que possuem em sua composição altas quantidades de compostos orgânicos influenciam positivamente no desenvolvimento no coleto de mudas.

Em relação ao VR (Figura 5) o tratamento contendo $80 \%$ de BC acrescido de solo, promoveu um 
melhor resultado na produção de mudas de açaí, com média de $0,90 \mathrm{~cm}^{3}$. A resposta do sistema radicular ao aumento da bagana é condizente com as condições físicas do material em função da maior porosidade e menor densidade do substrato. Assim uma maior possibilidade de exploração do substrato através das raízes, na qual propicia maior probabilidade de absorção de água e nutrientes, como foi observado por Nibau et al. (2008).

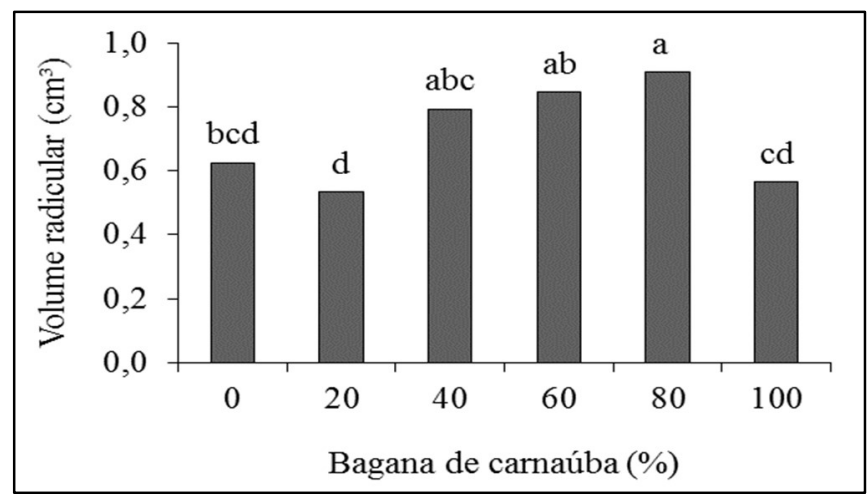

Figura 4: Volume da raiz de mudas de açaí cultivar BRS-Pará, em função de substratos com proporções de bagana de carnaúba acrescidos de solo.

A adição da concentração de bagana de carnaúba na composição do substrato promoveu um incremento na AF (Figura 6), os tratamentos com proporções de $80 \%$ e $100 \%$ de BC acrescidos de solo, promoveram melhores resultados com médias de $66,49 \mathrm{~cm}^{2}$ e $68,50 \mathrm{~cm}^{2}$ respectivamente. Provavelmente devido a uma maior disponibilidade de nutrientes principalmente o nitrogênio que está intimamente relacionado ao crescimento vegetativo das plantas e também a uma maior retenção de água.

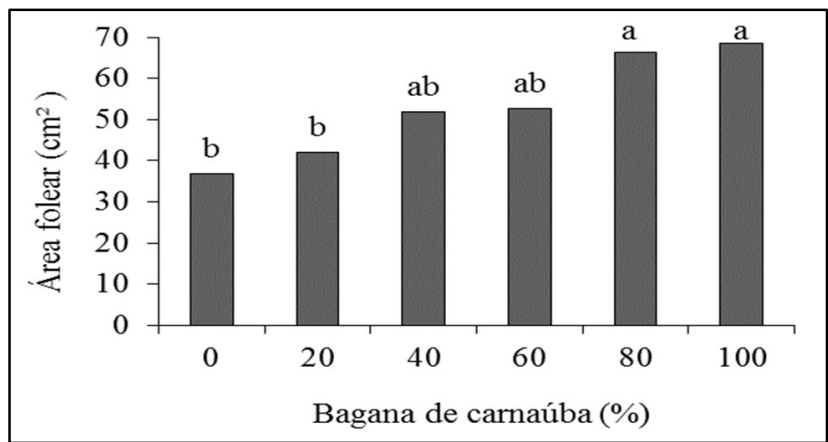

Figura 5: Área foliar de mudas de açaí cultivar BRS-Pará, em função de substratos com proporções de bagana de carnaúba acrescidos de solo.

Seabra Junior et al. (2004), relatam que quanto maior a área foliar certamente maior será a produção. Aragão et al. (2011), estudando o desenvolvimento de mudas de melão em diferentes tipos de substratos constataram melhor resultado para AF com o uso de $100 \%$ do substrato comercial Plantmax $\mathrm{HT}^{\circ}$. Duarte et al. (2008), constataram maior área foliar com $100 \%$ de casca de arroz como substrato na cultura do melão.

A respeito da MSPA os tratamentos contendo $60 \%$ e $80 \%$ de BC acrescidos de solo, foram os que se sobressaíram em relação aos demais, sendo os dois estatisticamente iguais, apresentado 0,5725 g e 0,6025 g, respectivamente (Figura 7A). Corroborando com os resultados obtidos neste estudo, Carneiro (1995), fazendo análise da massa seca da parte aérea e da raiz, constatou que o seu melhor crescimento de raiz é importante para dar suporte à biomassa verde produzida pelas plantas, sendo esse crescimento 
consequência da qualidade das sementes, do tipo e proporção do substrato (componentes físico, químico e biológico).

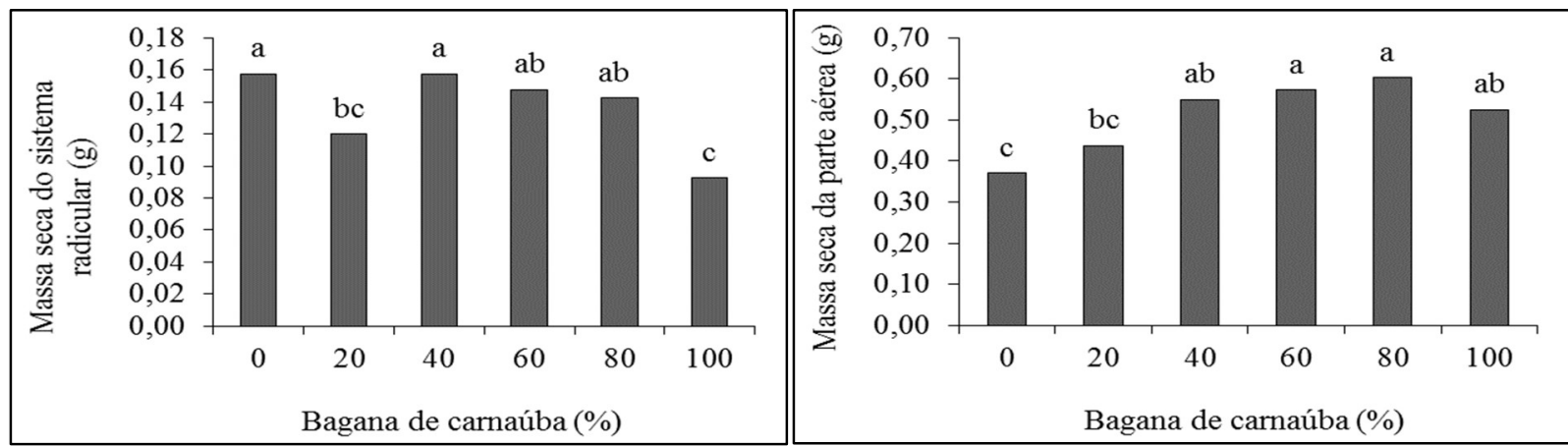

Figura 6: Massa seca da parte aérea (A) e Massa seca do sistema radicular (B) de mudas de açaí cultivar BRS-Pará, em função de substratos com proporções de bagana de carnaúba acrescidos de solo.

A bagana de carnaúba possibilita uma decomposição mais rápida por parte dos microrganismos e consequentemente disponibiliza nutrientes mais rapidamente para as mudas, o que favorece um melhor desenvolvimento das mesmas (SEABRA JUNIOR et al., 2004). Quanto aos resultados correspondentes à MSSR, observaram-se que os tratamentos compostos de $0 \%$ e $40 \%$ de BC acrescidos de solo, apresentaram melhores resultados, ambos pesando 0,1575 g (Figura 7B). Pode-se afirmar que as características físicas do substrato (Tabela 2) influenciaram positivamente no desenvolvimento da biomassa do sistema radicular.

Nota-se que houve um decréscimo na MSSR quando aumentou as proporções de bagana de carnaúba. Paiva Sobrinho et al. (2010) observaram que mudas de Eugenia dysenterica DC, Hancornia speciosa Gomes, Dipteryx alata Vog. Apresentaram maiores concentrações de massa seca em substratos compostos apenas com solo, aos 180 dias após a semeadura, sob condições controladas.

Em relação a característica IQD, foram encontrados resultados que variaram de 0,0650 a 0,0925 (Figura 9). Caldeira et al. (2012) afirmam que, quanto maior o valor desse parâmetro, melhor é a qualidade da muda, ou seja, os melhores valores foram obtidos nos tratamentos com $40 \%, 60 \%$ e $80 \%$ de BC acrescidos de solo, ambos apresentaram valores de 0,0925.

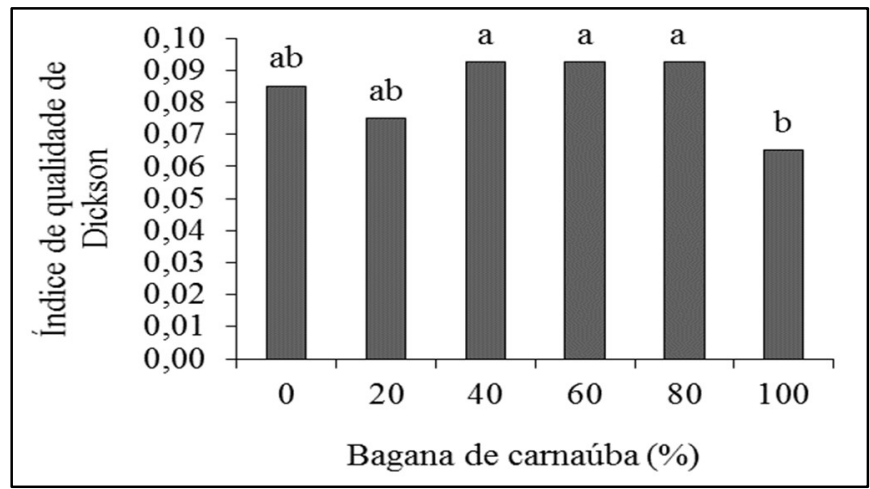

Figura 7: Índice de Qualidade de Dickson de mudas de açaí cultivar BRS-Pará, em função de substratos com proporções de bagana de carnaúba acrescidos de solo.

Para o cálculo de IQD, são considerados atributos morfológicos que expressam a robustez da muda, entre eles a massa seca da parte aérea e a massa seca do sistema radicular, atributos dependentes do 
crescimento das raízes (FERRAZ et al., 2011). Com isso, as mudas de açaí do T6, observou-se uma redução significativa no IQD. Isto pode ser atribuído não só ao efeito químico relacionado à disponibilidade de nutrientes, como também ao efeito físico que a adição de material orgânico proporciona no substrato, como menor densidade, maior porosidade, aeração e retenção de água (SOUSA et al., 2013).

De maneira geral, os maiores valores do IQD indicam plântulas de maior vigor e, consequentemente, melhor qualidade (ZUFFO et al., 2014). Sendo, portanto, um índice indispensável para avaliar e determinar a qualidade das mudas (SOUSA et al., 2013).

\section{CONCLUSÕES}

A bagana de carnaúba pode ser utilizada como substrato para produção de mudas de açaí 'BRS-Pará' nas proporções de $40 \%, 60 \%$ e $80 \%$, pois formam mudas com qualidade fitotécnica. No entanto, recomendase o uso de substrato de BC na proporção de $40 \%$ acrescido de solo, por esta combinação apresentar uma menor quantidade de bagana de carnaúba na sua composição e consequentemente um menor custo de produção.

\section{REFERÊNCIAS}

ARAGÃO, C. A.; PIRES, M. M. M. L.; BATISTA, P. F.; DANTAS, B. F.. Qualidade de mudas de melão produzidas em diferentes substratos. Revista Caatinga, v.24, n.3, p.209-214, 2011.

BECKMANN-CAVALCANTE, M. Z.; AMARAL, G. C.; CAVALCANTE, Í. H. L.; LIMA, M. P. D.. Alternative substrates for production of Heliconia psittacorum L. seedlings under shade and open field conditions. African Journal of Biotechnology, v.10, p.272-277, 2011. DOI: http://dx.doi.org/10.5897/AJB11.1028

BEZERRA, F. C.; FERREIRA, F. V. M.; SILVA, T. C.. Produção de mudas de berinjela em substratos à base de resíduos orgânicos e irrigadas com água ou solução nutritiva. Horticultura Brasileira, v.27, n.2, p.1348-1352,2009.

CALDEIRA, M. V. W.; DELARMELINA, W. M.; LÜBE, S. G.; GOMES, D. R.; GONÇALVES, E. O.; ALVES, A. F.. Biossólido na composição de substrato para a produção de mudas de Tectona grandis. Floresta, v.42, n.1, p.77-84, 2012. DOI: http://dx.doi.org/10.5380/rf.v42i1.26302

CARNEIRO, J. G. A.. Produção e controle de qualidade de mudas florestais. Curitiba: UFPR, 1995.

CARVALHO, N. M.; NAKAGAWA, J.. Sementes: ciência, tecnologia e produção. 4 ed. Jaboticabal: Funep, 2000.

CUNHA, A. M.; CUNHA, G. M.; SARMENTO, R. A.; CUNHA, M.; AMARAL, J. F. T.. Efeito de diferentes substratos sobre o desenvolvimento de mudas de Acácia sp. Revista Árvore, v.30, n.2, p.207-214, 2006.

DOI: https://doi.org/10.1590/S0100- 67622006000200007

DICKSON, A.; LEAF, A. L.; HOSNER, J. F.. Quality appraisal of white spruce and white pine seedling stock in nurseries. For.
Chron, v.36, p.10-13,1960. DOI:

https://doi.org/10.5558/tfc36010-1

DUARTE, T. S.; PEIL R. M. N.; BACCHIS, S.; STRASSBURGUER, A. S.. Efeito da carga de frutos e concentrações salinas no crescimento do meloeiro cultivado em substrato. Horticultura Brasileira, v.26, n.3, p.348-353, 2008. DOI: http://dx.doi.org/10.1590/S0102-0536200800030001

FARIAS, W. C.; OLIVEIRA, L. L. P.; OLIVEIRA, T. A.; DANTAS, L. L. G. R.; SILVA, T. A. G.. Caracterização física de substratos alternativos para produção de mudas. Revista Agropecuária Científica no Semiárido, v.8, n.3, p.1-6, 2012.

FERRAZ, A. V.; ENGEL V. L.. Efeito do tamanho de tubetes na qualidade de mudas de jatobá (Hymenaea courbaril L. VAR. stilbocarpa (Hayne) Lee Et Lang.), Ipê Amarelo (Tabebuia chrysotricha (Mart. Ex dc.) Sandl.) e Guarucaia (Parapiptadenia rigida (benth.) Brenan). Revista Árvore, v.35, n.3, p.413-423, 2011. DOI: https://doi.org/10.1590/S0100-67622011000300005

GONZAGA, L. M.; SILVA, S. S. S.; CAMPOS, S. A.; FERREIRA, R. P.; CAMPOS, A. N. R.; CUNHA, A. C. M.. Recipientes e substratos para a produção de mudas de jatobá (Hymenaea courbaril L.). Revista Brasileira de Agropecuária

Sustentável, v.6, n.1, p.64-73, 2016.

DOI: http://dx.doi.org/10.21206/rbas.v6i1.309

GUERRINI, I. A.; TRIGUEIRO R. M.. Atributos físicos e químicos de substratos compostos por biossólidos e casca de arroz carbonizada. Revista Brasileira de Ciências do Solo, v.28, n.6, p.1069-1076, 2004.DOI: https://doi.org/10.1590/S0100-06832004000600016

IBGE. Instituto Brasileiro de Geografia e Estatística. Levantamento Sistemático da Produção Agrícola. IBGE, 
2015.

LIMA, R. L. S.; SIQUEIRA, D. L.; WEBER, O. B.; CECON, P. R.. Teores de macronutrientes em mudas de aceroleira (Malpighia emarginata Dc.) em função da composição do substrato. Ciência e Agrotecnologia, v.30, n.6, p.1110-1115, 2006. DOI: https://doi.org/10.1590/S1413$\underline{70542006000600010}$

MAGUIRE, J. D.. Speed of germination-aid in selection and evaluation for seedling emergence and vigor. Crop Science, v.2, n.1, p.176-177, 1962.

DOI: https://doi.org/10.2135/cropsci1962.0011183X000200 $\underline{020033 x}$

MAPA. Ministério da Agricultura, Pecuária e Abastecimento. Instrução Normativa. DAS n.17, de 21 de maio de 2007. Brasília: DOU, 2007.

NEVES, L. T. B. C. N.; CAMPOS, D. C. S.; MENDES, J. K. S.; URNHANI, C. O.; ARAUJO, K. G. M.. Qualidade de frutos processados artesanalmente de açaí (Euterpe oleracea Mart.) e bacaba (Oenocarpus bacaba Mart.) Revista Brasileira de Fruticultura, v.37, n.3, p.729-738, 2015. DOI: https://doi.org/10.1590/0100-2945-148/14

NIBAL, C.; GIBBS, D. J.; COATES, J. C.. Branching out in new directions: the controlo of root architecture by lateral root formation. New Phytologist, n.179, p.159-614, 2008. DOI: https://doi.org/10.1111/j.1469-8137.2008.02472.x

NOGUeIRA, O. L.; FIGUEIRÊDO, F. J. C.; MULLER, A. A.. Açaí. Belém: Embrapa Amazônia Oriental, 2005.

OLIVEIRA, C. J.; PEREIRA, W. E.; MESQUITA, F. O.; MEDEIROS, J. S.; ALVES, S. A.. Crescimento inicial de mudas de açaizeiros em respostas a doses de nitrogênio e potássio. Revista Verde de Agroecologia e Desenvolvimento Sustentável, v.6, n.2, p.227-237,2011.

PAIVA SOBRINHO, S.; LUZ, P. B.; SILVEIRA, T. L. S.; RAMOS, D. T.; NEVES, L. G.; BARELLI, M. A. A.. Substratos na produção de mudas de três espécies arbóreas do cerrado. Revista Brasileira de Ciências Agrárias, v.5, n.2, p.238-243, 2010. DOI: https://doi.org/10.5039/agraria.v5i2a741

PAIVA, E. P.; MAIA, S. S. S.; CUNHA, C. S. M.; COELHO, M. F. B.; SILVA, F. N.. Composição do substrato para o desenvolvimento de mudas de manjericão (Ocimum basilicum L.). Revista Caatinga, v.24, n.4, p.62-67, 2011.

PASSOS, M. L. V.; ZAMBRZYCKI, G. C.; PEREIRA, R. S.. Balanço hídrico e classificação climática para uma determinada região de Chapadinha/MA. Revista Brasileira de Agricultura Irrigada, v.10, n.4, p.758-766, 2016. DOI:

http://dx.doi.org/10.7127/rbai.v10n400402

PORTINHO, J. Á.; ZIMMERMANN, L. M.; BRUCK, M. R.. Efeitos benéficos do açaí. Journal of Nutrology, v.5, n.1, p.15-20, 2012. DOI: http://dx.doi.org/10.1055/s-0040-1701423
SARAIVA, K. R.; NASCIMENTO, R. S.; SALES, F. L.; ARAUJO, H. F.; FERNANDES, C. N. V.; LIMA, A. D.. Produção de mudas de mamoeiro sob doses de adubação fosfatada utilizando como fonte superfosfato simples. Revista Brasileira de Agricultura Irrigada, v.5, n.4, p.376-383.

SCHMITZ, J. A. K.; SOUZA, P. V. D.; KAMPF, A. N.. Propriedades químicas e físicas de substratos de origem mineral e orgânica para o cultivo de mudas em recipientes. Ciência Rural, v.32, n.6, p.937-944, 2002. DOI: http://dx.doi.org/10.1590/S0103-84782002000600005

SEABRA JÚNIOR, S.; GADUN, J.; CARDOSO, A. I. I.. Produção de pepino em função da idade das mudas produzidas em recipientes com diferentes volumes de substrato. Horticultura Brasileira, v.22, n.03, p.610-613, 2004. DOI: https://doi.org/10.1590/S0102-05362004000300022

SILVA JÚNIOR, J. V.; CAVALCANTE, M. Z. B.; BRITO, L. P. S.; AVELINO, R. C.; CAVALCANTE, I. H. L.. Aproveitamento de materiais alternativos na produção de mudas de tomateiro sob adubação foliar. Revista Ciência Agronômica, v.45, n.3, p.528-536, 2014. DOI: http://dx.doi.org/10.1590/S1806$\underline{66902014000300013}$

SILVA, F. A. M.; SOUZA, I. V.; ZANON, J. A.; NUNES, G. M.; SILVA, R. B.; FERRARI, S.. Produção de mudas de juçara com resíduos agroindustriais e lodo de esgoto compostados. Revista Brasileira de Engenharia de Biossistemas, v.9, p.109-121, 2015. DOI: http://dx.doi.org/10.18011/bioeng2015v9n2p10

SILVA, F. A. S.; AZEVEDO, C. A. V.. The Assistat Software Version 7.7 and its usi in the analysis of experimental data. African Journal of Agricultural Research, v.11, n.39, p.37333740, 2016. DOI: https://doi.org/10.5897/AJAR2016.11522

SILVESTRE, W. V. D.; PINHEIRO, H. A.; SOUZA, R. O. R. M.; PALHETA, L. F.. Morphological and physiological responses of açaí seedlings subjected to different watering regimes.

Revista Brasileira de Engenharia Agrícola e Ambiental, v.20, n.4, p.364-371.DOI: https://doi.org/10.1590/18071929/agriambi.v20n4p364-371

SOUSA, W. C.; NÓBREGA R. S. A.; NÓBREGA, J. C. A.; BRITO, D. R. S.; MOREIRA, F. M. S.. Fontes de nitrogênio e caule decomposto de Mauritia flexuosa na nodulação e crescimento de Enterolobium contortsiliquum. Revista Árvore, v.37, p.969-979, 2013.DOI: https://doi.org/10.1590/S0100-67622013000500019

WELTER, M. K.; CHAGAS, E. A.; MELO, V. F.; CHAVES, D. B. Initial growth of açai seedlings in function of basaltb powder doses. International Journal of Agriculture Innovations and Research, v.3, n.1, p.18-23, 2014.

ZUFFO, A. M.; JESUS, A. P. S.; DIAS, S. G. F.. Posição de semeadura na emergência e desenvolvimento inicial de plântulas de baru. Pesquisa Florestal Brasileira, v.34, n.79, p.251-256, 2014. DOI: https://doi.org/10.4336/2014.pfb.34.79.650

A CBPC - Companhia Brasileira de Produção Científica (CNPJ: 11.221.422/0001-03) detém os direitos materiais desta publicação. Os direitos referem-se à publicação do trabalho em qualquer parte do mundo, incluindo os direitos às renovações, expansões e disseminações da contribuição, bem como outros direitos subsidiários. Todos os trabalhos publicados eletronicamente poderão posteriormente ser publicados em coletâneas impressas sob coordenação da Sustenere Publishing, da Companhia Brasileira de Produção Científica e seus parceiros autorizados. Os (as) autores (as) preservam os direitos autorais, mas não têm permissão para a publicação da contribuição em outro meio, impresso ou digital, em português ou em tradução. 